International Journal of Stem Cell Research and Transplantation (IJST)

ISSN: 2328-3548

\title{
Human Peripheral Blood Derived Hematopoietic Stem Cell: History, the Isolation Methods and Inves- tigation of Different Parameters Effects on Their Differentiation to the Body Cells
}

Research Article

Mohammadi $\mathrm{H}^{1}$, Mohammadnejad $\mathrm{J}^{2 *}$, Yavari $\mathrm{K}^{3}$

${ }^{1}$ Department of Life Science Engineering, Faculty of New Sciences and Technologies, University of Tehran, Tehran, Iran.

${ }^{2}$ Department of Life Science Engineering, Faculty of New Sciences and Technologies, University of Tehran, Tehran, Iran.

${ }^{3}$ Biotechnology lab, Nuclear Science and Technology Research institute, (NSTRI), Tehran, Iran.

Abstract
Blood and the system that forms it, known as the hematopoietic system, consist of many cell types with specialized functions. Red
blood cells (erythrocytes) carry oxygen to the tissues. Platelets (derived from megakaryocytes) help prevent bleeding. Granulocytes
(neutrophils, basophils and eosinophils) and macrophages (collectively known as myeloid cells) fight infections from bacteria, fungi,
and other parasites such as nematodes (ubiquitous small worms). Some of these cells are also involved in tissue and bone remodeling
and removal of dead cells. B-lymphocytes produce antibodies, while T-lymphocytes can directly kill or isolate by inflammation cells
recognized as foreign to the body, including many virus-infected cells and cancer cells. Many blood cells are short-lived and need to be
replenished continuously; the average human requires approximately one hundred billion new hematopoietic cells each day. The con-
tinued production of these cells depends directly on the presence of Hematopoietic Stem Cells (HSCs), the ultimate, and only, source
of all these. Peripheral blood stem cells (PBSC) are rapidly becoming the primary rescue modality for autologous transplantation and
are now actively being investigated in the allogeneic transplant setting. Many investigators and clinical researchers believe that PBSC
are likely to replace bone marrow stem cells entirely, for use in clinical transplantation in the not too distant. Hematopoietic stem cells
(HSCs) are the blood cells that give rise to all the other blood cells. They give rise to the myeloid (monocytes and macrophages, neutro-
phils, basophils, eosinophils, erythrocytes, megakaryocytes/platelets, dendritic cells), and lymphoid lineages (T-cells, B-cells, NK-cells).
The definition of hematopoietic stem cells has changed in the last two decades. The hematopoietic tissue contains cells with long-term
and short-term regeneration capacities and committed multipotent, oligopotent, and unipotent progenitors.

\section{*Corresponding Author:}

Javad Mohammadnejad,

Department of Life Science Engineering, Faculty of New Sciences and Technologies, University of Tehran, Tehran, Iran.

Tel: +98 21 61118582; Fax: +982161118582

E-mail: Mohamadnejad@ut.ac.ir

Received: March 09, 2014

Accepted: April 01, 2014

Published: April 03, 2014

Citation: Mohammadi H, Mohammadnejad J, Yavari K. (2014). Human Peripheral Blood Derived Hematopoietic Stem Cell: History, the Isolation Methods and Investigation of Different Parameters Effects on Their Differentiation to the Body Cells, Int J Stem Cell Res Transplant, 02(02), 59-62. doi: http://dx.doi.org/10.19070/2328-3548-1400010

Copyright: Mohammadnejad J $\subset$ 2014. This is an open-access article distributed under the terms of the Creative Commons Attribution License, which permits unrestricted use, distribution and reproduction in any medium, provided the original author and source are credited.

\section{Introduction}

\section{Peripheral Blood}

Peripheral blood cells are the cellular components of blood, consisting of red blood cells, white blood cells, and platelets, which are found within the circulating pool of blood and not sequestered within the lymphatic system, spleen, liver, or bone marrow. Stem cells are small, round cells with a squat nucleus and scant surround- ing cytoplasm. Although unremarkable in appearance, stem cells can perform what have been called "acts of biological resurrection." Whereas other types of cells in the body have a limited lifespan and die after dividing their endowed number of times, a stem cell can reproduce forever. The stem cell is immortal (in cellular terms). A stem cell can forgo immortality and turn into an ordinary blood cell, a red blood cell (an erythrocyte), a white blood cell (a leukocyte), or a large cell (a megakaryocyte) that fragments into the platelets needed for blood to clot. All stem cells, regardless of their source share three general properties: they are able of dividing and renewing themselves for long period, they are unspecialized and they are able to differentiate into any specialized cell types. The real pluripotent stem cells are issued from the embryo. Specifically, embryonic stem cells are derived from eggs fertilized in vitro and isolated from a microscopic ball of cells, the blastocyst, formed four or five days after the fertilization. These cells can give rise to every tissues of the human body and represent a huge reservoir of regenerative cells. But for some ethical consideration as well as some hazards appeared during embryonic stem cells transplantation (high incidence of teratoma or terat ocarcinoma), researchers have redirected their attention upon primitive cells residing in the adult body. Each organ and tissue is perceived to possess a sub-population of cells capable of self maintenance activated for the normal turnover of tissue or in case of organ injury.

\section{The stem cell extraction and isolation methods from Pe- ripheral blood}

Approximately $100 \mathrm{ml}$ of healthy adult peripheral blood was col- 
lected in K2Epreloaded tubes. Bloods samples were processed as soon as possible on the day of collection according to two different protocols to isolate the EPC. For the 'direct' approach, unmanipulated human blood was diluted in EGM and directly placed in culture, as described by Reinish et al. This approach expected EPC colony formation after 1-2 weeks For the alternative approach, the MNCs fraction was isolated from human blood by density-gradient centrifuging. Isolated MNCs were then placed in culture and EPC colony formation was expected after 3-4 weeks in culture

\section{Multi Lineages Differentiation Potential}

Last but not least, the more important point is the capacity of stem cells to differentiate into other lineages to permit the regeneration of specific organ. As classical source of HSC, the majority of the experiments have been realized from bone marrow. It has been demonstrated that UCB-SC contain the largest percentage of the most immature pluripotent CD34+ cells which can react more strongly to in vitro cytokine stimulation and produce a lot of progeny cells. From the results, the authors showed that UCB-SC have the better ability to self-renew and to give rise to large clones of primitive progeny. These results confirm that the larger proportion of primitive HSC reside in the UCB and could adopt different lineages. Recently, thanks to microarray technology, the powerful tool which permits the profiling of thousand of genes in one single experiment, we start to better understand the molecular mechanisms which regulate HSC activity

\section{Availability of HSC}

The number of stem cells in the adult is very low. The proportion of HSC differs according to the source: the largest fraction in the BM and the poorest in the UCB38. Nevertheless, as shown previously6, the proportion of HSC in the PB could be dramatically increased by injection of cytokine such as rhG- CSF prior to the collection without any risk for the patient. Besides, recently, improvement in HSC mobilization has been achieved by the use of AMD3100, a selective antagonist of CXCL12, also known as stromal cell derived factor-1 (SDF-1) that binds to its receptor CXCR4 expressed on CD34+ cells surface. It is indeed wellknown that SDF-1 plays a central role in CD34+ homing in the $\mathrm{BM}$ and AMD3100, by decreasing the interactions between SDF1 and CXCR4 induces rapid stem cells mobilization in the circulating blood and could as well acts synergistically with rh-G-CSF.

\section{Peripheral blood stem cell (PBSC) collection}

Peripheral blood stem cell (PBSC) collection is a procedure where volunteer donors or patients donate their stem cells through apheresis for allogeneic and autologous blood and marrow transplantation. At Children's, most PBSC collections are for autologous transplants. A variety of diseases are treated particularly neuroblastoma and malignant brain tumors

\section{Stem cell apheresis}

Apheresis is the process of extracting blood components from the peripheral blood with the help of a cell separator that divides blood into separate cell elements. Because few stem cells travel in the bloodstream, it takes several hours (most within one day) to collect a sufficient quantity for transplantation. Children's uses cutting-edge monitoring equipment in the Hematopoietic Stem Cell Laboratory that allows the stem cell transplant team to know precisely when, in real time during the procedure, the optimum quan-

\section{Comparison between Peripheral Blood Stem Cells and Cord Blood Donated for Transplantation}

\begin{tabular}{|c|c|}
\hline Peripheral Blood & Cord Blood \\
\hline $\begin{array}{l}\text { Bone marrow donation requires surgery under general anesthesia. Donors may ex- } \\
\text { perience temporary discomfort and/or pain. Long-term consequences of growth } \\
\text { factors used in peripheral blood stem cell donations are uncertain. }\end{array}$ & $\begin{array}{l}\text { When obtained from the delivered placenta and umbilical cord, cord blood dona- } \\
\text { tion poses no medical risk to mother or infant }\end{array}$ \\
\hline $\begin{array}{l}\text { A transplant requires donation of a quart or more of bone marrow (mixed with } \\
\text { blood). }\end{array}$ & $\begin{array}{l}\text { A small volume (sometimes few ounces) can be used for transplantation. The } \\
\text { number of cells needed depends on the recipient's weight. }\end{array}$ \\
\hline $\begin{array}{l}\text { Bone marrow and peripheral blood grafts contain large numbers of stem cells. } \\
\text { Engraftment of neutrophils is rapid. }\end{array}$ & $\begin{array}{l}\text { Cord blood units contain smaller numbers of stem cells. Slower engraftment may } \\
\text { lead to prolonged hospital stay, and in certain cases, to serious complications. }\end{array}$ \\
\hline $\begin{array}{l}\text { After a formal search is started, it usually takes } 2 \text { or more months to transplant, if } \\
\text { a donor is available. }\end{array}$ & $\begin{array}{l}\text { When a match is found, it can take only a few days for confirmatory and special } \\
\text { testing for shipment to the Transplant Center (less than } 24 \text { hours in an emer- } \\
\text { gency). }\end{array}$ \\
\hline $\begin{array}{l}\text { Potential donors may no longer be available or may have withdrawn consent. } \\
\text { Donor must be found and retested to confirm the HLA typing and infectious dis- } \\
\text { ease results and to confirm that the donor is still willing and able to donate bone } \\
\text { marrow. Significant donor attrition. }\end{array}$ & Once frozen, a cord blood unit is available until used. There is no donor attrition. \\
\hline $\begin{array}{l}\text { Donor may be available to give a second transplant or to donate blood for T-cells } \\
\text { if necessary. }\end{array}$ & Donor is not available for a second donation \\
\hline $\begin{array}{l}\text { Bone marrow is used fresh (shelf-life measured in hours). Peripheral blood stem } \\
\text { cells usually stored for short term (days to a few months). }\end{array}$ & $\begin{array}{l}\text { Cord blood units are cryopreserved (stored in special freezers). Frozen cord blood } \\
\text { has been transplanted successfully after up to } 13 \text { years in storage. }\end{array}$ \\
\hline $\begin{array}{l}\text { Patient must begin conditioning before the bone marrow or peripheral bloods } \\
\text { harvest. Coordination between donation and transplant is critical and complex. }\end{array}$ & $\begin{array}{l}\text { Cord blood graft can be shipped to the transplant center before the patient enters } \\
\text { the hospital and begins conditioning for transplantation. Coordination is simple. } \\
\text { Cord blood units are shipped on demand. }\end{array}$ \\
\hline $\begin{array}{l}\text { Latent viral infection in the donor is common (i.e. CMV }>50 \% \text { in U.S. adult } \\
\text { donors). }\end{array}$ & Latent viral infection in the cord blood donor is rare (i.e. CMV $<1 \%$ in U.S.). \\
\hline No risk of transplanting a genetic disease. & $\begin{array}{l}\text { There is a small probability that a rare, unrecognized genetic disease affecting the } \\
\text { blood or immune system of the baby may be given with the cord blood transplant. }\end{array}$ \\
\hline Severe graft vs host disease (GvHD) is common with mismatched grafts. & GvHD less frequent, usually less severe and easier to treat \\
\hline $\begin{array}{l}\text { Generally requires a perfect match between donor and recipient for } 8 / 8 \text { HLA-A, } \\
-\mathrm{B},-\mathrm{C} \text { and -DRB1 antigens. Additional HLA factors (HLA-DQ and -DP) increas- } \\
\text { ingly used to improve prognosis. }\end{array}$ & $\begin{array}{l}\text { HLA-mismatched cord blood transplants are possible, making it easier to find a } \\
\text { suitable match. Role of HLA-C, -DQ and -DP are not yet known. }\end{array}$ \\
\hline
\end{tabular}


tity of stem cells have been collected. Infants and young children may require ongoing sedation during the apheresis procedure, and in these cases only, stem cell collections occur in the pediatric intensive care unit (PICU). Older children undergo apheresis in the Blood and Marrow Transplantation inpatient unit at the hospital

\section{5 years of peripheral blood stem cell transplantation}

It has been 25 years since peripheral PBSCT was introduced as a transplant modality. This anniversary, therefore, marks the first clinical evidence that circulating hematopoietic stem cells are capable of completely and permanently regenerating a lymphohematopoietic system after myeloablative treatment. Even more fundamental and Beyond transplant aspects, the capability of hematopoietic blood stem cells to regenerate And maintain equal cellular concentration throughout all marrow spaces in the human body attributes to them a homeostatic function that had until then never been shown Before in a clinical setting.

\section{First successful autologous PBSCTs}

The autologous transplant modality required a liquid nitrogen cryopreservation technique for large volume leukapheresis products. Such a method was developed allowing stem cells to accumulate over the course of several daily collections until an engraftment dose was reached. Thus, with the apheresis and cryopreservation technologies in place, blood stem cell infusions were first attempted in 1981 at Hammersmith Hospital in London, England, in patients with accelerated phase chronic myeloid leukemia (CML); the patients' stem cells had been harvested in earlier chronic phase with the intent of achieving a second chronic phase.[15] In the same year, at Johns Hopkins Hospital in Baltimore, Maryland, a "normal" blood stem cell harvest and transplantation attempt was undertaken in a patient with CML in cytogenetic remission. After myeloablative treatment and blood stem cell infusion there was first evidence of fast and complete hematopoietic reconstitution, although long-term stem cell engraftment could not be documented. It was another 5 years in 1986, before a patient with Burkitt's lymphoma underwent myeloablative radio- and chemotherapy followed by PBSCT at Heidelberg University Hospital in Germany. Hematopoietic reconstitution was fast and complete. Twenty-five years later, the patient remains alive without evidence of disease and with normal lymphohematopoietic function. In 1986 and 1987, similar reports of successful PBSCTs were documented by research groups at the University of Nebraska Medical Center,[18] the Hospital Haut Leveque in Bordeaux, France,[19] and the Royal Adelaide Hospital in Adelaide, Australia.[20] In all of those initial PBSCT cases, stem cells were collected by multiple apheresis procedures at steady state without hematopoietic growth factor mobilization treatment.

\section{Strategies to increase peripheral blood stem cell concentra- tion}

In contrast to the well established BM transplantation, the use of PB stem cells in the mid 1980s seemed cumbersome mainly because in non-CML patients numerous steady state apheresis procedures were required to achieve an engraftment stem cell dose. For PBSCT to be accepted as a mainstream treatment modality, strategies to temporarily increase PB stem cell concentration had to be developed. One strategy was to induce a rebound of PB stem cell concentration follow- ing non-myelotoxic chemotherapy and short-term myelosuppression. Another strategy was to temporarily expand the PB stem cell pool by administering hematopoietic growth factors.

\section{Results}

We still cannot say with certainty if the fibroblastoid cells (fibroblast-like) that can be obtained through liquid culture of peripheral blood are the same cells as fibrocytes or circulating mesenchymal cells, because the surface markers, concretely CD34 -which is an indicator of the status as a hemopoyetic stem cell-, are expressed in fibrocytes [5] and in the cells described by Zhao et al[7] and is negative in mesenchymal cells[6]. Our results show evidence of a clear expression of CD34+ in fibroblastlike cells that, in addition to the positivity to vimentin (a connective tissue marker) and the NBT-test (an indicator of phagocytic activity), points to a cell with common characteristics of the stem cells, monocytes-macrophages, and fibroblasts. The lack of uniformity in the expression of surface markers, as documented in the scientific literature, certainly is related to the variability of the culture conditions, including the number of seeded cells, the culture media, the concentration of bovine fetal serum, the culture periods, stimulation factors for differentiation, and the methods for detecting surface markers (immunocytochemistry or flux activated cytometry).

\section{Conclusion}

Among the HSC, we have reviewed the numerous advantages of the UCB subset as these cells are easily accessible by a non invasive collection process, in vitro amplifiable, well-tolerated and last but not least possess more primitive molecular characteristics that confer them a higher flexibility. Significant progress have been made in recent years by the use of three-dimensional collagen or fibronectin porous scaffolds which promote new tissue formation by providing a surface and void volume that promote the attachment, proliferation and differentiation of the stem cells. Nevertheless, tissue engineering is currently only used in a limited number of clinical applications as bioengineered skin for burns. It may be unnecessary first to isolate and differentiate HSC in vitro but rather to mobilize endogenous stem cells from the circulating blood to home to the damaged area. Some experiments with animals have shown encouraging results by injecting growth factors to mobilize endogenous stem cells to the site of injury in a model of heart damage. In summary, the different approaches for tissue engineering are very promising and undoubtedly, HSC will play a key role in the development of cellular therapy for a variety of diseases. However, the biological properties and the interactions between stem cells and their environment have to be more investigated to be able, soon, to control their destiny in an appropriate way.

\section{References}

[1]. Weissman IL. Stem cells: units of development, units of regeneration, and units in evolution. Cell. 2000;100:157-68.

[2]. Castro-Malaspina H, Gay RE, Resnick G, Kapoor N, Meyers P, Chiarieri $\mathrm{D}$, et al. Characterization of human bone marrow fibroblast colony-forming cells (cfu-f) and their progeny. Blood. 1980;56:289-301.

[3]. Zhao Y, Glesne D, Huberman E. A human peripheral blood monocytederived subset acts as pluripotent stem cells. Proc Natl Acad Sci USA. 2003;100:2426-31

[4]. Park BH, Fikrig SM, Smithwick EM. Infection and nitroblue-tetrazolium reduction by neutrophils. A diagnostic acid. Lancet. 1968;2:532-4.

[5]. Barry FP, Murphy JM. Mesenchymal stem cells: Clinical applications and biological characterization. Int J Biochem Cell Biol. 2004;36:568-84.

[6]. Bossolasco P, Cova L, Calzarossa C, Rimoldi SG, Borsotti C, Deliliers GL, Silani V, Soligo D, Polli E: Neuro-glial differentiation of human bone marrow stem cells in vitro. Exp Neurol 2005, 193:312-325. 
[7]. Caplan AI: Review: mesenchymal stem cells: cell-based reconstructive therapy in orthopedics. Tissue Eng 2005, 11:1198-1211.

[8]. Hunter N: Scrapie and experimental BSE in sheep. Br Med Bull 2003, 66:171-183

[9]. Le Blanc K, Pittenger M: Mesenchymal stem cells: progress toward promise. Cytotherapy 2005, 7:36-45.

[10]. He Q, Wan C, Li G: Concise review: multipotent mesenchymal stromal cells in blood. Stem Cells 2007, 25:69-77.

[11]. Kim YC, Ntambi JM: Regulation of stearoyl-CoA desaturase genes: role in cellular metabolism and preadipocyte differentiation. Biochem Biophys Res Commun 1999, 266:1-4.

[12]. Song L, Webb NE, Song Y, Tuan RS: Identification and functional analysis of candidate genes regulating mesenchymal stem cell self-renewal and multipotency. Stem Cells 2006, 24:1707-1718.

[13]. Welte K, Gabrilove J, Bronchud MH, Platzer E, Morstyn G. Filgrastim (r-metHuGCSF): the first 10 years. Blood. 1996;88(6):1907-29.

[14]. Richman CM, Weiner RS, Yankee RA. Increase in circulating stem cells following chemotherapy in man. Blood.1976;47:1031-9.

[15]. Delassus S, Cumano A. Circulation of hematopoietic progenitors in the mouse embryo.Immunity.1996;4(1):97-106.

[16]. Goodman JW, Hodgson GS. Evidence for stem cells in the peripheral blood of mice. Blood.1962;19:702-14.

[17]. Storb R, Epstein RB, Ragde H, Bryant J, Thomas ED. Marrow engraftment by allogeneic leukocytes in lethally irradiated dogs. Blood.1967;30:805-11.
[18]. Freireich EJ, Judson G, Levin RH. Separation and collection of leukocytes. Cancer Res.1965;25:1516-20.

[19]. McCredie KB, Hersh EM, Freireich EJ. Cells capable of colony formation in the peripheral blood of man. Science.1971;171:293-4.

[20]. Micklem HS, Anderson N, Ross E. Limited potential of circulating haemopoietic stem cells. Nature.1975;256:41-3.

[21]. Hershko C, Gale RP, Ho WG, Cline MJ. Cure of aplastic anaemia in paroxysmal nocturnal haemoglobinuria by marrow transfusion from identical twin: Failure of peripheral-leucocyte transfusion to correct marrow aplasia. Lancet.1979; 1(8123):945-7

[22]. Bond VP, Cronkite EP, Fliedner TM, Schork P. Deoxyribonucleic acid synthesizing cells in peripheral blood of normal human beings. Science. 1958;128:202-3.

[23]. Brecher G, Cronkite EP. Post-radiation parabiosis and survival in rats. Proc Soc Exp Biol Med.1951;77:292-4.

[24]. Storb R, Graham TC, Epstein RB, Sale GE, Thomas ED. Demonstration of hemopoietic stem cells in the peripheral blood of baboons by cross circulation. Blood.1977;50:537-42.

[25]. JACKSON KA, MAJKA SM, WANG H, et al. Regeneration of ischemic cardiac muscle and vascular endothelium by adult stem cells. J Clin Invest 2001; 107: 1395-1401. 